\section{Ethics in preventive medicine: 1}

SIR

The article by Dr Petr Skrabanek, Why is preventive medicine exempted from ethical constraints?, and your own editorial $(1,2)$ quite rightly point out that, in comparison to ethical issues in the field of therapeutic medicine, little or no attention is paid to similar issues in the field of preventive medicine and health promotion.

Allow me however to be surprised that both texts ignore three books which analyse and describe exactly the problems you and Dr Skrabanek have referred to. The titles of these books show how relevant they are to the issues, problems and dilemmas described.

1. Ethical Issues in Preventive Medicine (1985) Martinus Nijhoff, 2. Ethical Dilemmas in Health Promotion (1987 and 1990) Wiley and Sons, 3. Ethics in Health Education (1990) Wiley and Sons. Furthermore among the contributors in these books one finds many of the better known scientists in medical ethics.

As editor of these three books I know that they have been obtained by many universities and medical libraries and I hope that they will help to inform and sensitise, not only health professionals, but also scientists of other disciplines and eventually decision-makers to the many and serious ethical problems in these fields.

\section{References}

(1) Skrabanek P. Why is preventive medicine exempted from ethical constraint? Fournal of medical ethics 1990; 16: 187-190.

(2) Gillon R. Ethics in health promotion and prevention of disease [editorial]. Fournal of medical ethics 1990; 16: 171-172.

SPYROS DOXIADIS, OBE, MD, FRCPE, MD (Hon) Upps

Foundation for Research in Childhood, 42 Amalias Street, 10558 Athens, Greece.

\section{Ethics in preventive medicine: 2}

SIR

I enjoyed reading the recent article by Dr Skrabanek (1) about ethics (or lack of ethics) in preventive medicine. This is an issue of increasing concern to me.

Of particular importance in primary prevention is that, by definition, the participants in programmes are healthy. Unethical decisions will affect people who have been previously entirely or apparently healthy (2). There must be a systematic assessment of risks and benefits for each programme. The risks of adverse effects to individuals have to be balanced against the benefits to the community. It is essential that participants in preventive programmes are fully informed of these risks and benefits.

As well as the ethical dilemmas faced by preventive medicine practitioners, there are also dilemmas faced by participants in programmes. An important one, relevant to vaccination programmes for the prevention of communicable disease, is that noncompliers with vaccines will penalise others. Non-compliers reduce the level of herd immunity and may ultimately contribute to outbreaks of disease. This again emphasises the importance of risk-benefit calculations, and the effective communication of same to participants in programmes. Only then is it possible to make informed decisions.

I congratulate Dr Skrabanek on his article and strongly support his suggestion of a forum to identify the ethical problems posed by preventive medicine and health promotion. There is an urgent need to bring the issues into focus.

\section{References}

(1) Skrabanek P. Why is preventive medicine exempted from ethical constraints? Fournal of medical ethics 1990; 16: 187-190.

(2) Doxiadis S, ed. Ethical dilemmas in health promotion. Chichester: John Wiley and Sons, 1987.

ANTHONY G CAPON, MBBS BMedSc, PhD, FAFPHM

Deputy Head, Public Health and Epidemiology Unit, Menzies School of Health Research, PO Box 41096, Casuarina, Northern Territory 0811, Australia. Member of the Institutional Ethics Committee of the Royal Darwin Hospital and the Menzies School of Health Research. 